\title{
Research on Urban Fresh Products Cold Chain Distribution Management System
}

\author{
Jiuyi An, Feng Han \\ Beijing Wuzi University, Beijing, China \\ Email: anjiuyi@126.com
}

Received 16 October 2015; accepted 16 November 2015; published 19 November 2015

Copyright (C) 2015 by authors and Scientific Research Publishing Inc.

This work is licensed under the Creative Commons Attribution International License (CC BY). http://creativecommons.org/licenses/by/4.0/

(c) (i) Open Access

\begin{abstract}
Fresh agricultural products have the characteristics of short storage period, easy pollution, easy metamorphism, etc. If storage or distribution process is not handled properly, it will produce a large loss in the circulation process, reduce the shelf life, and reduce the value of agricultural products, related to supply chain related business profit, and also related to food hygiene and safety. Based on the analysis of the demand and the characteristics of the cold chain distribution, and the analysis of the structure of the distribution system, the paper puts forward some reasonable suggestions for the improvement of the city cold chain distribution management system.
\end{abstract}

\section{Keywords}

Urban Fresh Agricultural Products, Cold Chain Distribution, Management System

\section{Introduction}

With the continuous upgrading of urban modern consumption, e-commerce technology, as well as the growing diversity of urban commercial development model, these make the small batch, multi frequency, timeliness strong fresh agricultural products cold chain the growing demand for direct distribution, residential distribution and the door to door distribution. This also gave birth to some of the problems related to the development of China's urban development and urban distribution, mainly in three aspects (Yu, 2013) [1]: The first is the competition for resources between urban distribution function and other urban functions; second is internal contradictions in urban distribution operations; third is how to meet the government's handling of the conflict between the consumer and the urban management.

The problem of city distribution is becoming more and more prominent; to solve the problem of city distribution gradually puts on the agenda of governments at all levels. Among the paper named "Logistics Industry Restructuring and Revitalization Plan” by Guo Fa [2009] which promulgated by State Council, city distribution 
was included in nine projects, raised to high priority development. Planning rules clearly pointed out, "to speed up the construction of urban logistics distribution projects, encourage professional transportation enterprises to carry out urban distribution, improve the level of urban distribution, solve the city express delivery, city distribution vehicles, parking and loading and unloading operations, and improve the urban logistics distribution network." In 2013, under the guidance of national overall framework of logistics development, Ministry of Transport, Ministry of Public Security, the National Development and Reform Commission [2], Industry and Information Department, Housing and Urban Construction Department, Ministry of Commerce, and the State Post Bureau jointly issued “On the Strengthening and Improvement of the Urban Distribution Management” (delivery [2013] No. 138) [3], which made it clear that to strengthen the management of urban distribution, and strive to use 5 years of time to establish the basic operation, and effective supervision of the urban distribution management system and operational mechanism. Government tries to use "management regulations, policy guidance, technical support” combination way to solve the contradiction between the demand of city distribution and city planning, facilities, traffic congestion, and environmental protection.

Agricultural products cold chain distribution system is "vegetable basket" project that is one of the important support systems of public which is the government's concern; the public concerned about the "food basket" project. Fresh agricultural products have the characteristics of short storage period, easy pollution, easy metamorphism, etc. If storage or distribution process is not handled properly, it will produce a large loss in the circulation process, reduce the shelf life, and reduce the value of agricultural products, related to supply chain related business profit, and also related to food hygiene and safety. Cities are the main places which demand for fresh agricultural products; the mass of fresh agricultural products with high efficiency, high-quality distribution to retail shops, restaurants and consumers are the reason why a city must have a logistics activity.

This paper mainly discusses the demand and characteristics of urban agricultural cold chain distribution, and the structural analysis of the mechanism of the distribution system, and proposes the development suggestions on cold chain distribution management system.

\section{Urban Agricultural Cold Chain Distribution Demand and Characteristics Analysis}

With the continuous improvement of urban residents consumption level and consumption capacity, consumption of fresh produce scale rapid growth in our country, the residents represent the diversification, freshness and nutrition of the other aspects of higher demand of agricultural products, particularly concerns about the safety of agricultural products. Cities cold chain distribution has become a necessary means to enhance the quality of agricultural consumption, reduce nutrient loss, ensure safety of agricultural products, it is necessary to ensure that meet consumer demand. Urban distribution is distribution services within the city and outskirts of the city provide customers with a range of a plurality of terminals and a modern logistics in a comprehensive, special form activities (Niu Xiuming, 2013). Urban agricultural cold chain distribution as a special form of urban distribution, provide services including fresh agricultural products processing, packaging, storage, refrigeration to urban and countryside. Put the fresh product to customers with the characteristic of timing, location, quantitative distribution within a reasonable range of the urban economy. Urban agricultural cold chain distribution plays an extremely important role in the whole nexus of agricultural supply chain, it's not due to the people's livelihood, but also care about the quality and safety of agricultural products, subject to the government and industry attention.

At present, playing a leading role in the circulation of urban agricultural products is wholesale market. However, the distribution channels of agricultural diversification trend is clearly, the supermarket chains, industrial base (Agricultural Enterprise Group) direct distribution model, agricultural e-commerce and other new distribution Delivery mode development rapidly. Based on the analysis of agricultural products circulation patterns, urban agricultural cold chain distribution requirements represent in the following areas:

1) City agricultural Products Wholesale Market demand for cold chain distribution. Agricultural wholesale is the urban agricultural distributor household, agro-processing enterprises, agricultural logistics service providers gathered place, but also agricultural products cold chain distribution requirements assembly point, at present, the main body of wholesale market is individual businesses and small-scale agricultural marketing enterprises, agricultural cold chain distribution scale is scattered and have greater randomness, modern cold chain distribution pattern be shipped fewer. 2) Urban Agriculture Products Cold Chain retail distribution requirements. In de- 
veloped countries, sales of fresh produce or produce mainly by supermarket chains and food stores, fresh foods take $80 \%$ of total consumption in chain enterprises, the United States is as high as 95\% (Li Min, Liu Yun, 2001) [4]. With the development of the consumption and the escalation of consumption patterns, supermarkets have gradually become an important sales terminals for fresh agricultural products, the demand for cold chain distribution became more and more. Retail chains cold chain distribution requirements including: First, the supplier is responsible for direct distribution of agricultural products to Chain enterprises stores; The second is to achieve integrated supplier dispersion distribution through retailers operate their own distribution centers, implementation of the Joint Distribution; Third is to use a third-party logistics companies cold chain distribution center, different suppliers through third-party distribution centers distribute to the stores unified, thereby improving vehicle loading rate and reduce distribution costs. From the development of urban cold chain distribution, agricultural retail chain cold chain distribution rate is relatively high and the distribution model is more advanced. 3) City e-commerce needs of agricultural Cold Chain Delivery. Agricultural products e-commerce cold chain has the characteristics of small quantities, multi-batch, rapid, timely and accurate. For e-commerce support urban agricultural cold chain distribution is the inevitable choice of fresh produce e-commerce development. Urban agricultural cold chain distribution demand is reflected in the following aspects: The first is self-built cold chain logistics distribution system, with self-distribution as the main mode. Second, relying on third-party cold chain logistics enterprises to integrate social logistics and achieve delivery in common for logistic resources, to achieve the purpose of controlling distribution costs; Second, Sharing with fresh produce supermarkets, convenience stores, community stores, wholesale markets and other business entities Enterprise Logistics Resource, achieving delivery in common. 4) The requirements of urban dining agricultural products cold chain distribution, the strong development momentum of chain restaurant industry, including fast food, hotels, and restaurants and other enterprises, internal business model. In order to ensure the catering enterprise product's quality assured, Cold chain distribution service system for the catering business came into being. Catering cold chain distribution originated in "foreign fast food", foreign fast-food chain enterprises cold chain logistics service system is relatively complete, from the production base of cold chain logistics center, fresh processing center to city chain logistics distribution center, it has formed a complete cold-chain logistics system. Catering enterprises city cold chain distribution pattern is mainly outsourced third-party cold chain logistics businesses operate.

Based on cold chain distribution needs analysis, urban agricultural cold chain distribution has the following particularity:

1) Distribution object (agricultural products) perishable nature. Agricultural products cold chain distribution's object is fresh agricultural products, the storage and transportation process decreased with the time increase, even deterioration and decay. Because the deterioration and decay characteristic of agricultural products, it capped the logistics time, and also limits the logistics radius, and asked to minimize the number of transport (Huang Zuhui, Liu Yingdong, 2005) [5]. The objective attribute determines the agricultural distribution process needs to take additional measures and means to ensure product quality and quality and safety, reduce losses, prevent pollution, thus increasing the difficulty and cost of delivery. 2) Timeliness and irreversible of the process. Fresh of seafood, vegetables, meat, milk, eggs and other agricultural products have a certain timebound, with the development of time, the fresh degree is gradually decreased, product quality and safety problems will occur. At the same time, due to the reduction and irreversible of product quality for temperature changed, also makes agricultural products cold chain distribution process irreversible, this requires the accurate and security in distribution process. 3) The special nature of facilities and equipment. We must consider the different types of fresh agricultural product's requirements of temperature during cold chain distribution, maintain a suitable temperature, use of specific equipment or preservation of cold chain equipment, when equipped the cold store, also Equipped refrigerated transport vehicle and insulated containers and other cryogenic facilities, make fresh product in all aspects of circulation is always in a suitable low temperature environment. 4) Distribution requirements body's feature of pluralism, changeable, dispersion. Agriculture Products Cold urban distribution's primary task is to provide services for urban residents, Its clients are retail shops, community shops, catering companies, the enterprises and institutions and consumers, distribution of agricultural products which have a huge flow and flow changing characteristics, reflects the service characteristics of small-volume, multispecies, high frequency, up close and door to door in the logistics distribution process. 5) Delivery operational complexity. Demand characteristics of urban distribution system is more customers, small batch, multi-frequency, time management demanding and difficult. Customer demand is generally in small quantities and multiple batches, in order to achieve economies of scale and distribution requirements, it need to fully utilize the 
capacity of the car, improve load rate, distribution companies often use a car for multiple customers in the same area to process distribution mode. In urban complex traffic environment, it increases the complexity of device configuration and distribution processes. 6) Distribution activities with a social attributes. Urban agricultural cold chain distribution is not a simple "traffic" or "logistics" problems, agricultural product of the city cold chain distribution as the livelihood projects named "vegetable basket", it is more focused on the city's operating objectives, not just corporate operational goals, it requires the city overall harmony, and not just the distribution process efficiency. In essence, urban distribution is under government controlled condition, A tripartite distribution of market supply and demand sides completed (supply and demand side and the government side) linkage service mechanism. This is the nature of the distribution of urban basic position, it specifies the system has the demand-side and provider in distribution services, put the market rules as the basic rules in operating; Urban distribution market system is the market with many market management objects. The government has played an important role in the market system, market system is the basic structure of urban distribution layer (Yu Kaiyuan, 2011) [1].

\section{Urban Agricultural Cold Chain Distribution Architecture Analysis}

30 years of reform and opening up, the rapid development of urban circulation system of agricultural products, Initially formed the main agricultural products wholesale market, which is supported by all level farmer market, a variety of Retail Business as a network terminal, combined with Field supply and local production, urban agricultural product distribution center constantly improve circulation pattern, meet the needs of product of all level of people, and played an important role in maintain social stability.

1) The constitute of urban agricultural cold chain distribution system's main body

Cities cold chain distribution of agricultural products subject mainly refers to the various organizations that achieve the logistics functions in the agricultural products flow within the city limits. Distribution is a key factor in the agricultural product distribution system that be formed. Different entities combined to form a different distribution model in various ways, Distribution body's binding pattern is the basis and premise of distribution operation. On the basis of the main binding modes, it can further discuss the implementation of distribution activities, It includes distribution center facility location, route planning, vehicle selection, and information systems and building a information platform, etc. Urban agricultural cold chain distribution status is complex, it related to the distribution body single farmers, the rural specialized cooperative economic organizations, agricultural products processing enterprises, farm produce wholesale markets, farmers' markets, community shops, large supermarket chains, third-party cold chain logistics enterprises, etc. With the rise of e-commerce of agricultural products, e-commerce businesses have become one of body distribution, in which community convenience stores, property companies as the distribution end to delivery and staging points are also included in the home delivery system.

2) Urban agricultural cold chain distribution process constitutes

Urban agricultural cold chain distribution process consists three core areas (Hu Yunchao, Shen Jingsheng, 2012) [6]: Conversion equipment, distribution and transportation, end unloading and delivery, shown in Figure 1. a) Conversion loaded link. Converting link is the process of regional bulk cargo centralized, sorting, equipped with other operations in peri-urban freight station. The purpose is to adapt the limits for large trucks into the city, and according to the customer's cargo transport needs effectively combined to form economic and reasonable cargo batch. b) Distribution and transportation links. Distribution transport links means that stowage goods served by customer demand, usually is a short-range, low-volume, high-frequency modes of transport. There are many factors effect the distribution and transportation, these include changes in traffic flow, road construction, changes in distribution of customers, mobilize for change vehicles, and other factors, they affect each other, it's easy to cause the not timely delivery, distribution route choice inappropriate, delaying delivery times, illegal break-line and other issues, thus increasing the distribution of the extra cost. c) The end of the unloading and distribution sectors. The end of the loading and unloading service link refers the process of goods loading in shopping malls, supermarkets and other cargo. From the view of urban distribution status, it exist distribution vehicle docked difficult and difficult loading and unloading issues, lead the truck parking in the lane for long time and loading long time, thereby increasing the parking cost and time cost in ending load link.

With the development of electronic commerce, receipt time of the end consumer became uncertainty, this increase the difficulty and cost in the end delivery. In order to solute the issue, delivery system will be close to the 


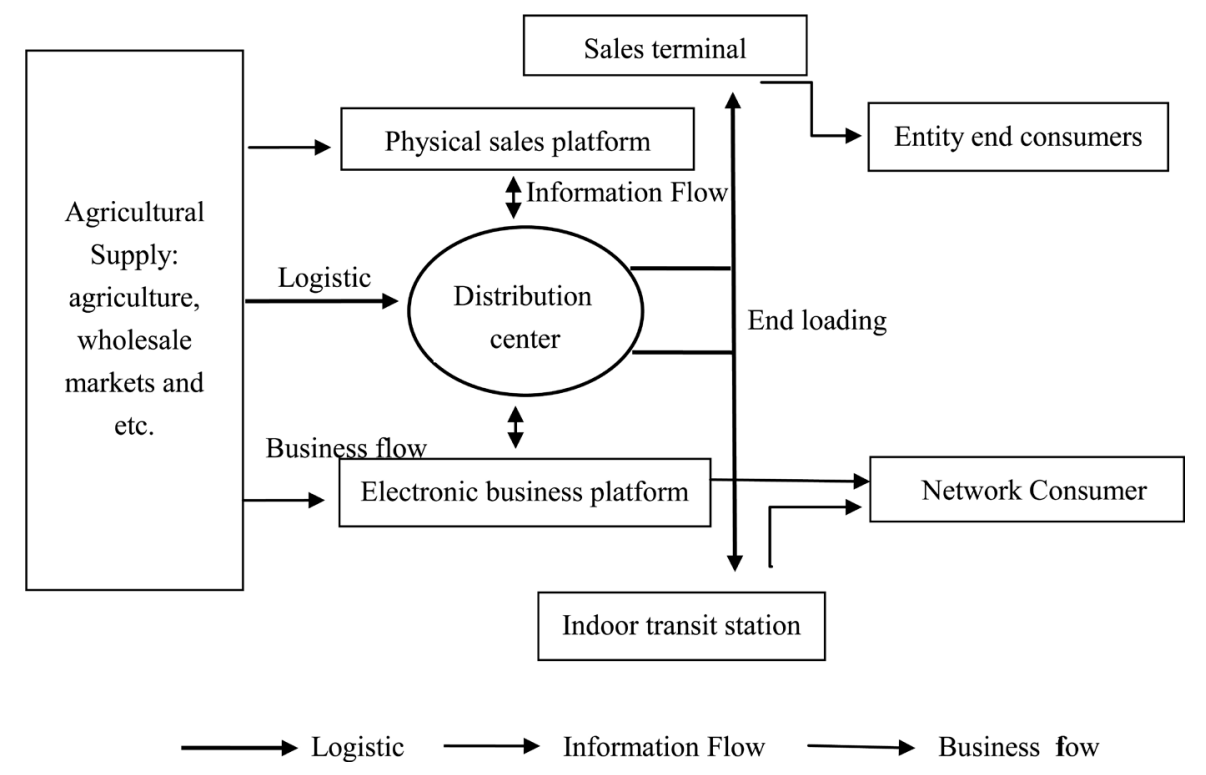

Figure 1. Urban agricultural cold chain distribution process structure.

consumer community convenience stores, agricultural community stores, property companies and other end of the network incorporate to the Delivery System. As the end of the distribution system of staging or delivery point, in order to save time and cost.

\section{Urban Agriculture Products Cold Chain Management System Development Strategies and Suggestions}

This article summarizes the urban agricultural wholesale markets, urban retail chain, agricultural e-commerce, chain restaurant's need to urban cold chain distribution of major agricultural city circulation mode, based on the above requirements, eight characteristics of urban cold chain distribution is proposed: a) The perishable of distribution object (agricultural products). b) Timeliness and irreversible process. c) Particularity facilities and equipment. d) Distribution requirements body pluralism, changeable, dispersion. e) Distribution operational complexity. f) Distribution activities with a social property. Based on the summary of cold chain distribution needs of the city and feature, as well as analysis of the structural mechanism of distribution system, proposed the development suggestion on cold chain distribution management system are as follows:

1) Integration of resources

By the overall level of economic and agricultural development constraints, urban agricultural cold chain distribution status are complicated, distribution network system also is the pattern that combined with rural specialized cooperative economic organizations, agricultural products processing enterprises, farm produce wholesale markets, farmers markets, community shops, large supermarket chains, third-party cold chain logistics companies. The complexity and uncertain in cold chain distribution process asked they should through the integration of resources to achieve different distribution collaboration between the body and the organizational model, it need to establish reliable and trust relationship between the structure of mutual by integrating mechanism. Network resources integration of urban agricultural products cold chain distribution can start from two aspects: The one is reconfigure the retail chain and different formats of e-commerce horizontal network resources. Achieve conservation through shared logistics resources, as well as benefit-sharing and risk-sharing. Second, the distribution network resources horizontal integration. Different companies have different resources advantage, the enterprises can achieve complementary advantages through horizontal consolidation effect. Combining the successful experience of domestic and foreign typical urban distribution development and trends, joint distribution is the resource integration model results, through the push related the optimal allocation of resources, improve the intensive level of urban distribution, reduce urban traffic pressure of urban freight vehicles.

2) Encourage innovation

Urban cold chain distribution is a systematic project, it's related to institutional, planning and policy, tech- 
nology and other aspects of the problem. With the increasing scale of circulation of agricultural products and the diversification of sales channels, the existing logistics mode is hard to match, innovation is the inevitable choice of solving urban cold-chain distribution problems. The one is the distribution service innovation. As by conducting the night distribution services, solve the problem of "fighting for passenger and cargo", improve load factor by Joint distribution, and solve the problem of heavy traffic, etc. Second, system innovation. Government departments often impose restrictions of trucks into the city management policies for ensuring the movement of persons. This regulatory policy is difficult to balance traffic management and security "basket" project, system innovation through innovative vehicle standard policy, nighttime transportation support policies, trading Facilities regulatory policies to make the lane smooth is the right way. Third, technological innovation. Urban cold chain distribution problems are often subject to technology, how to reach the purpose of energy conservation and environmental protection through energy-saving technology innovation refrigerated trucks, through IT Innovation, Information sharing between supply chain subject to wait for the delivery time and improve the accuracy of distribution, etc.

3) Strengthen policy support

Because of the agricultural products is closely related to urban consumer life, and itself has the characteristic of perishable, government should introduce some preferential policies to guarantee a smooth distribution of agricultural products, enhanced support, guidance and supervision and management from the policy level. In view of the current urban distribution facing logistics distribution vehicle into the city, traffic loading and unloading parking problems, it lead the enterprise logistics cost rising, increase the roundabout traffic, interference to urban traffic became serious, increase the social cost and environmental cost, etc. Urban management department can make a difference in the following a parts: First, clear station construction land policy; Second, clear vehicle standards policy guidance; Third, improve vehicular traffic policy; Fourth, commerce facilities parking regulatory policies.

\section{Conclusion}

In short, the cold chain distribution system of agricultural products is an important support system for the government to pay attention to the "vegetable basket" project. This paper is to reduce the loss of fresh agricultural products in the circulation process, reduce the shelf life of agricultural products, and further enhance the supply chain related enterprises to provide theoretical support for the profit. It also provides a theoretical basis for the government to improve the urban distribution of agricultural products to develop operational programs.

\section{Acknowledgements}

The fund project, the National Social Science Fund "The research of fresh agricultural products cold chain logistics management system for the needs of the city" (11BJY111).

\section{References}

[1] Yu, K.Y. (2011) City Distribution-Oriented Transformation Mechanism. Commercial Research, 3, 177-180.

[2] (2010) National Development and Reform Commission National "Five” Agricultural Cold Chain Logistics Development Plan. National Development and Reform Commission, 1-6.

[3] Urban Development of Joint Distribution (2013) Cow Hideaki Logistics Technology (Equipped Version). Construction, 3, 20-23.

[4] Li, M. (2011) New Urban Agricultural Distribution System. Anhui Agricultural Sciences, 39, 5370.

[5] Huang, Z.H. and Liu, D.Y. (2005) China’s Logistics System Construction and Agricultural System Analysis. Agricultural Economic Issues, 4, 49-53.

[6] Hu, Chao, Shen, J.S. and Wong, A.-L. (2012) Urban Green Logistics Distribution System. Logistics Technology, 31, 56-59. 